\title{
Ocular surface squamous neoplasia in a patient with AIDS
}

\author{
Catherine J. Choi MD MS, Nahyoung Grace Lee MD
}

- Cite as: CMAJ 2017 May 15;189:E700 doi: 10.1503/cmaj.161005

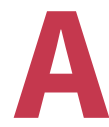

33-year-old Hispanic man with a new diagnosis of AIDS and a CD4 count of $0.02 \times 10^{9} / \mathrm{L}$ presented with a six-month history of an enlarging lesion on the surface of his right eye, which caused blurry vision and irritation. On examination, there was an elevated, gelatinous, papilliform lesion at the nasal aspect of the eye, measuring $6.9 \mathrm{~mm} \times 7.5 \mathrm{~mm}$ and extending onto the cornea, without intraocular involvement (Figure 1A). Enlarged feeder vessels were present nasal to the lesion (Figure 1B). The patient underwent a wide local excision, double freeze-thaw cryotherapy to the conjunctival and limbal (corneal) margins, and alcohol epitheliectomy of the cornea. Amniotic membrane and fibrin glue were used to reconstruct the surface of the eye. Histopathologic examination showed conjunctival squamous cell carcinoma in situ, extending to the temporal margin. Map biopsies of the superior, inferior and temporal quadrants were negative for tumour.

Ocular surface squamous neoplasia (OSSN) is the most common nonpigmented malignant disease of the surface of the eye, comprising $7 \%$ of all conjunctival tumours. The overall estimated prevalence is 1.9 per 100000 per year. ${ }^{1,3}$ In the HIV-positive population, there is a 12 -fold increase in risk of OSSN. ${ }^{3}$ Of patients less than 50 years of age with OSSN, 50\% were HIV positive. ${ }^{3}$ In addition, OSSN in HIV-positive patients is more aggressive - with larger and thicker tumours, higher incidence of deep invasion, and poorer prognosis, requiring enucleation or exenteration - than in the more common demographic of older, fair-skinned patients. ${ }^{2}$

\section{References}

1. Verma V, Shen D, Sieving PC, et al. The role of infectious agents in the etiology of ocular adnexal neoplasia. Surv Ophthalmol 2008;53:312-31.

2. Kamal S, Kaliki S, Mishra DK, et al. Ocular surface squamous neoplasia in 200 patients: a case-control study of immunosuppression resulting from human immunodeficiency virus versus immunocompetency. Ophthalmology 2015;122:1688-94.

3. Weinstein JE, Karp CL. Ocular surface neoplasias and human immunodeficiency virus infection. Curr Opin Infect Dis 2013;26:58-65.
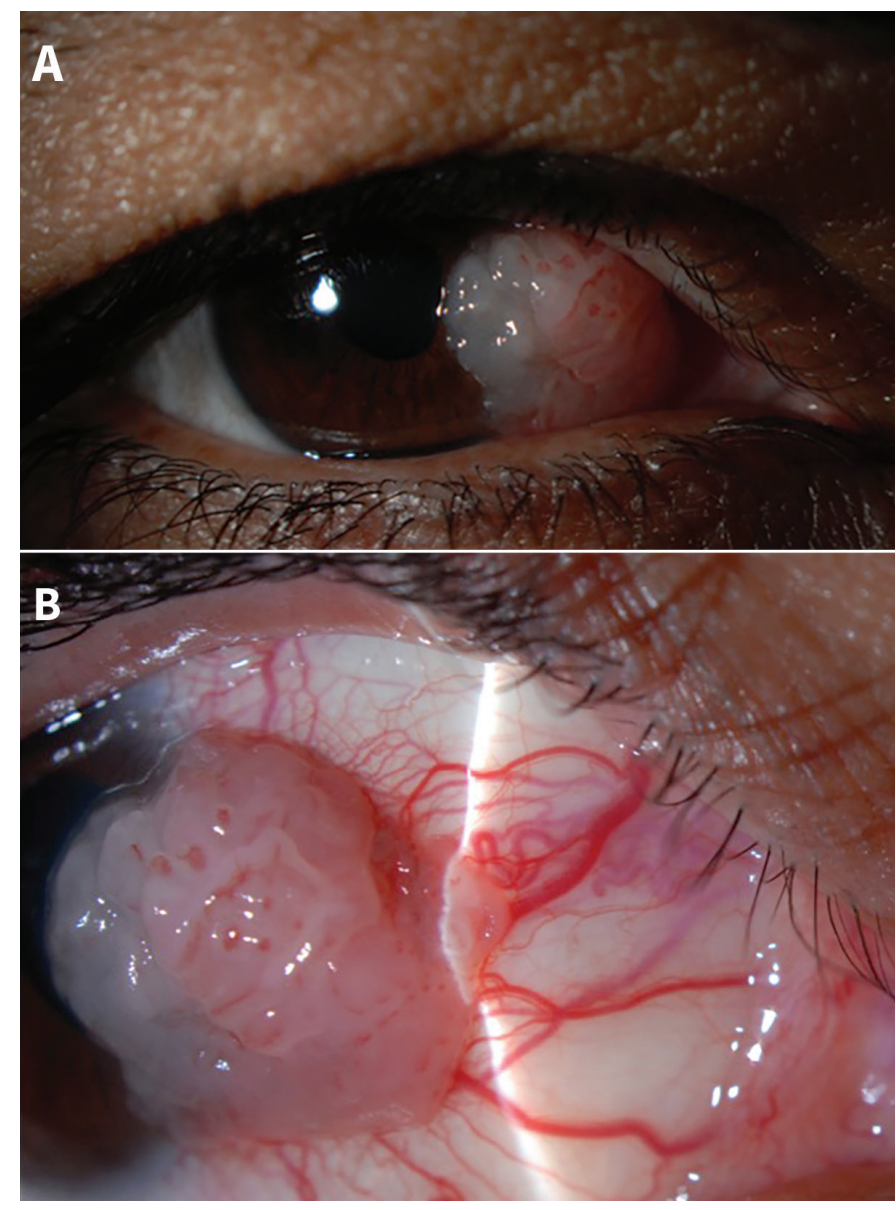

Figure 1: (A) Gelatinous, papilliform lesion at the nasal aspect of the right eye in a 33-year-old Hispanic man with AIDS. (B) Slit-lamp examination showing enlarged feeder vessels and elevation at the nasal-most aspect of the lesion.

\section{Competing interests: None declared.}

This article has been peer reviewed.

The authors have obtained patient consent.
Affiliation: Department of Ophthalmic Plastic Surgery, Massachusetts Eye and Ear Infirmary, Boston, Mass.
Correspondence to: Catherine Choi, catherinechoi@post.harvard.edu 